\title{
Normative data and repeatability for macular ganglion cell layer thickness in healthy Swedish children using swept source optical coherence tomography
}

Philip Wolf ${ }^{1}$, Eva Larsson ${ }^{2}$ and Hanna Åkerblom ${ }^{1,2,3^{*}}$ (D)

\begin{abstract}
Background: Optical coherent tomography (OCT) technology is evolving with improved resolution and accuracy in segmentation between different cell layers in the retina. The ganglion cell layer in the macula region is a window to see what is happening in the visual pathways and a macula OCT is an examination that most children tolerate. This makes updated normative data necessary since variables may differ between different OCT devices and normative data for children is often not presented.

The aim of this study was to develop normative data for macular ganglion cell layer thickness in children, measured with swept source OCT, and investigate the repeatability between measurements.

Methods: Healthy Swedish children between 4 and $16 y e a r s$ old, with normal refraction, spherical equivalent mean:1.13 (sd:0.66) dioptre and normal visual acuity Logmar, mean: 0,015 (sd:0,05), were examined with swept source OCT. Macula OCT was performed three times in both eyes and the different retinal layers were evaluated.

Results: Fifty-eight children were screened for inclusion. Fifty-five children were included in the study, 24 boys and 31 girls. Mean age was 8.9 years. Results from right eyes was analysed. The mean average thickness of macular ganglion cell layer thickness, retinal nerve fibre layer/ganglion cell layer boundary to inner plexiform layer/inner nuclear layer boundary, was $68.0 \mu \mathrm{m}$ (sd:4.0, range:58-77). There was no correlation with sex or age. Fifty-three children manage to complete two, and 41 children three acceptable measurement and the mean coefficient of variation was low.

Conclusion: The ganglion cell layer thickness differs according to which OCT device that is used, and the population examined. This makes normative data essential to accurately interpret results. Swept source OCT of the macula have excellent repeatability and the examination well tolerated in most children making it an investigation useful for diagnosing and following diseases in the optic pathways.
\end{abstract}

Keywords: Macula, Ganglion cell layer, Children, OCT

${ }^{*}$ Correspondence: hannamcarlsson@hotmail.com

1 Department of Ophthalmology, Region Västmanland, Västerås, Sweden

Full list of author information is available at the end of the article

\section{Background}

Optical coherence tomography (OCT) was described in 1991 and introduced in clinical practice 1995 as a cross sectional examination of the retina $[1,2]$. Today, OCT is available as a standard examination in most eye clinics. Since 1995 the technology has evolved with improved resolution of examinations which in turn leads 
to improved accuracy in segmentation between different cell layers in the retina. New OCT devices are continuously being developed and updated normative data is necessary since variables may differ between different OCT devices [3].

In OCT software, available normative data are based on adults. In a paediatric population normative data is of importance to correctly distinguish retinal pathology from normal variations. Previously, several studies have been published using different OCT-devices in children [4-6]. Recently Asian paediatric populations have been studied describing the normative data for children using Triton swept source OCT (Topcon Medical Systems, Inc., Oakland, USA) [7, 8].

In children with diseases affecting the optic nerve and visual pathway ophthalmological examination can be challenging due to compliance issues and especially when it comes to visual field testing using computerized or manual perimetry. In adults, a correlation regarding macular ganglion cell layer (GCL) thickness and visual field abnormalities in glaucoma has been shown [9]. The GCL complex (GCC) is gaining increased interest and has shown signs of retrograde thinning not only after lesions to the optic nerve but also due to occipital lesions [10-12]. Several studies have been made regarding the peripapillary retinal nerve fibre layer (RNFL) in children [13]. However, examining the RNFL and GCL using the macula programme might be easier in children than examining the optic nerve as the latter requires fixating to the side instead of straight forward when performing the OCT-scan. Good correlation between right and left eyes in our setting has earlier been established [14].

The primary aim of this study is to present normative data in a Swedish paediatric population regarding retinal thickness and thickness of GCL using the macular programme with swept source OCT. A secondary aim was to investigate the repeatability of the different measurements.

\section{Methods}

Children aged 4-16 years were invited to participate and examined after obtaining informed consent from the child and their custodians. Recruitment was initialized in participating eye clinics where children were examined by other reasons. They were also recruited by personal communication.

The inclusion criteria were absence of eye disease, uncorrected or best corrected visual acuity of $0.1 \mathrm{Log}$ MAR or better, refraction in cycloplegia not exceeding $+/-3.0 \mathrm{D}$ in spherical equivalent and astigmatism 2.0 $\mathrm{D}$ or less. Intraocular pressure was not measured in this study.
Assessments were performed at the Department of Ophthalmology, Västmanland Hospital, Västerås and at the Department of Ophthalmology, Uppsala University Hospital, Uppsala, Sweden. Monocular visual acuity was assessed using digital linear LogMAR charts and if the participant was unable to read, a HVOT chart [15] at $3 \mathrm{~m}$ distance was used. Cycloplegia was achieved using eye drops containing cyclopentolate $0,85 \%$ and phenylephrine 1,5\%. Autorefractor determined cycloplegic refraction. Topcon DRI OCT-1 Triton (Topcon Medical Systems, Inc., Oakland, USA) swept source OCT was used and three consecutive $7 \times 7 \mathrm{~mm}$ cube 3D Macula OCT-examinations centered on the fovea were performed in each eye, right eye first. If scan was deemed unreliable or showing artefacts it was repeated until three acceptable scans were completed, or the examination was aborted if no further successful scans were to be expected. Data were reviewed using IMAGEnet ${ }^{\circledR} 6$ (Topcon Medical Systems, Inc., Oakland, USA). Retinal tissue layers were automatically segmented by the Topcon Advanced Boundary Software "TABS"

Fifty-eight children were examined for inclusion in the study and 55 children were included. All 55 included participants had at least one OCT-scan of good quality. Quality was assessed by manual review for artefacts (blinking and eye movements) and segmentation errors. The left eye was then examined. No adjustments regarding segmentation were needed in the accepted scans. Fifty-three participants had two scans and 41participants managed the full three scans with good quality of the right eye. Corresponding number of successful exams for the left eye was 52; 45 and 32 . We chose to use the results from the right eye for further analysis and in the case of multiple exams averages were used in the calculation of mean values.

Three children did not meet inclusion criteria due to (hyperopia above 3D $(n=1)$, unacceptable examination quality/extensive artefacts in all scans $(n=2)$.

Analysed areas were total average, superior and inferior fraction and in 6 sector grids.

GCIPL is defined as retinal nerve fibre layer/ganglion cell layer boundary (RNFL/GCL) to inner plexiform layer/inner nuclear layer boundary (IPL/INL) and GCC is defined as inner limiting membrane (ILM) to IPL/INL.

\section{Statistical methods}

Data was analysed using IBM SPSS Statistics for Windows, (Version 24.0. Armonk, NY: IBM Corp). Normal distribution was examined using Kolmogorov-Smirnov test. Correlations were assessed Pearson correlation test. Intra-session coefficient of variation $(\mathrm{CV})$, that is the standard deviation divided by the mean, were calculated for all variables. Intraclass correlation (ICC) were 
Table 1 Descriptive data of the 55 children included in the study (right eyes)

\begin{tabular}{llll}
\hline & & Mean (SD) & Range \\
\hline Age & Years & $8.9(3.1)$ & $5-16$ \\
Visual acuity & logMAR & $0.015(0.05)$ & $-0.1-0.1$ \\
Refraction SE & Dioptres & $1.13(0.66)$ & $-0.25-+2.75$
\end{tabular}

SE Spherical equivalent, $S D$ standard deviation calculated for all repeated examinations. A CV close to 0 and ICC 1.0 is regarded as perfect.

\section{Results}

Fifty-five children, (24 boys), met the inclusion criteria with acceptable quality of examinations, see Table 1.

Total mean average for GCIPL was $68.0 \mu \mathrm{m}$ (sd:4.0, range:58-77) and for GCC was $107.1 \mu \mathrm{m}$ (sd:6.5, range:92-120). Values for superior and inferior GCL thickness, GCIPL, GCC and segmentation lines are presented in Fig. 1.

Retinal thickness, GCIPL and GCC are presented in Table 2.

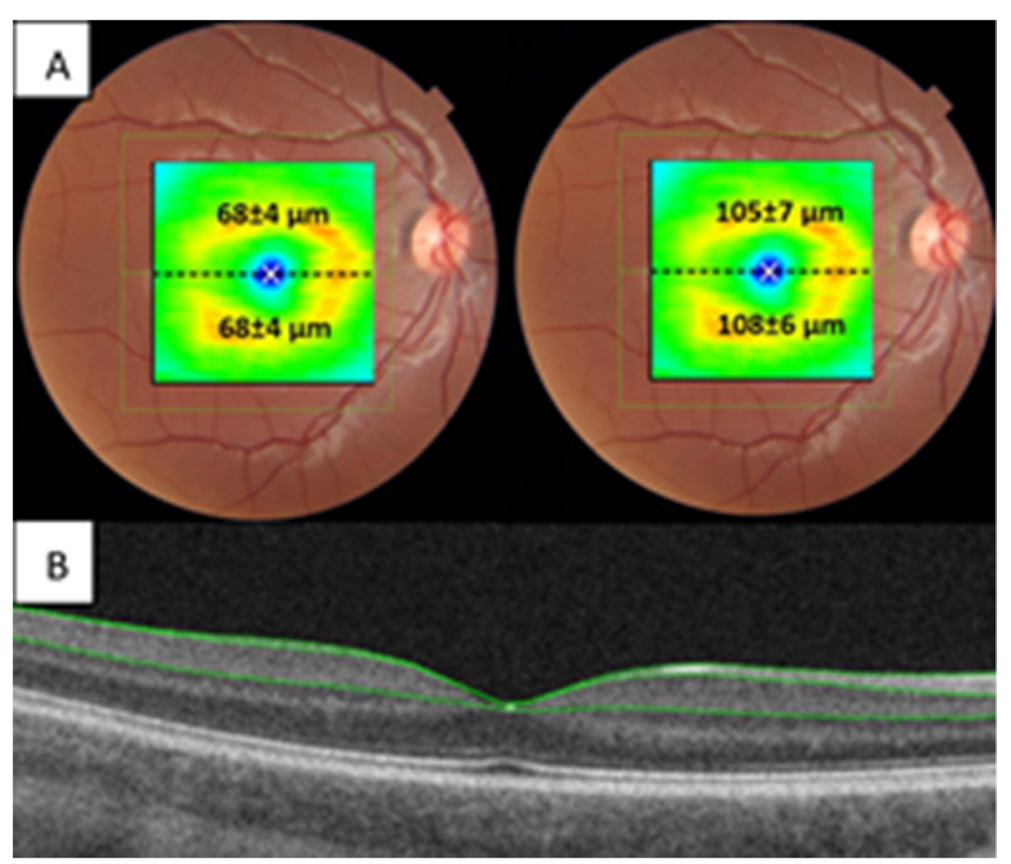

Fig. 1 A. Macular ganglion cell layer (GCL). Average values of superior/inferior GCL-IPL (top left) and GCC (top right) thickness, 7x7mm square measurement shown in figures $\mathbf{B}$. Bottom figure shows segmentation boundaries, ILM (internal limiting membrane) top green line, RNFL/GCL (retinal nerve fibre layer/ganglion cell layer) middle green line, IPL/INL (inner plexiform layer/inner nuclear layer) bottom green line. GCIPL: RNFL/ GCL to IPL/INL. GCC: ILM to IPL/INL

Table 2 Retinal and ganglion cell layer thickness $(\mu \mathrm{m})$ in 6 sector grid

\begin{tabular}{lllllll}
\hline Sector & \multicolumn{2}{l}{ Retina ILM-RPE } & & GCIPL & & \multicolumn{2}{c}{ GCC } \\
ILM-INL
\end{tabular}




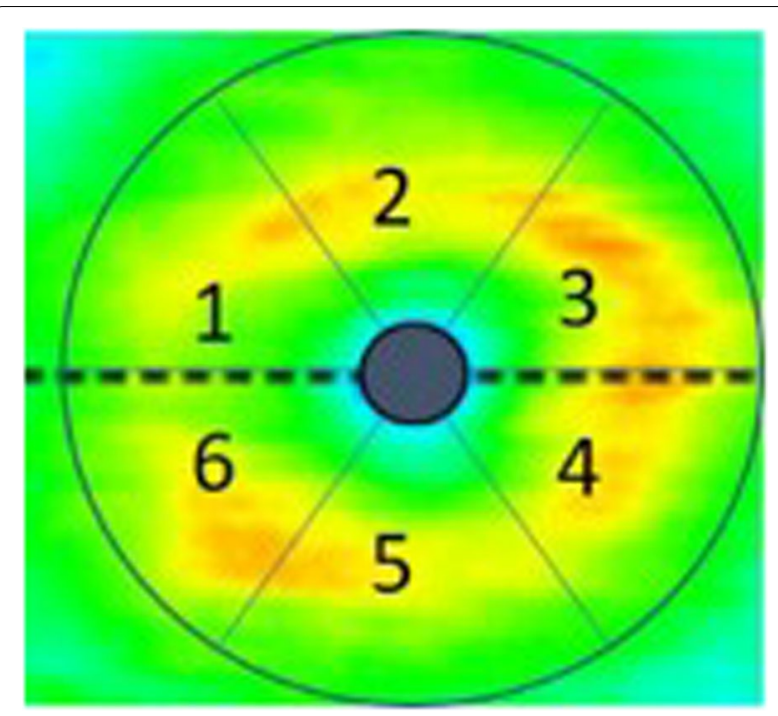

Fig. 26 sector grid of the macula, right eye

GCIPL and GCC analysed in 6 sector grids are shown in Fig. 2.

There were no correlations with age in GCIPL and GCC, r:0.12, p:0.37 and $\mathrm{r}: 0.22, \mathrm{p}: 0.11$ respectively. There were no correlation with sex and GCIPL and GCC, r:0.02, p:0.89 and r:-0.04, p:0.79 respectively.

Median CV for total average, superior, inferior and the 6 sector grids for GCIPL and GCC was between 0.6 and $1.1 \%$, see Fig. 3. ICC was $>0.9$ for all presented variables.

\section{Discussion}

In this study we present normative data for thickness of macular GCL in healthy Swedish children with normal visual acuity and refraction, measured with swept source OCT.

Previous studies have described the thickness of the macular GCL in children, but the majority are performed with different OCT techniques [16, 17]. Arnljost et al. reported group of Swedish 6.5 year-old children using the Cirrus HD-OCT device [6]. The mean average GCL thickness was $85.9 \mu \mathrm{m}$ (sd:5.3) which is thicker than in the present study however due to different devices used the results are not comparable.

Lee et al. presented retrospective data of macular GCL thickness measured with swept source OCT and in their group of healthy Korean children between 3 and 17 years old, the mean average thickness was $71.6 \mu \mathrm{m}$ range: 49.3-87.2 [7]. The refraction in the group varied from -12 to +7.75 and a multivariate analysis showed a correlation with refraction, making the results difficult to compare to the present study. Cheng et al. have used the same OCT technique in a large cohort study with healthy Chinese children [8]. They presented the results as mean average GCL thickness in the macula as well as in the ETDRS charts and compared to the present study those children had a thicker average macular GCL. The refraction in their study had a range of -11.38 to +8.38 and they found a correlation between thickness and refraction, where higher myopia was correlated to thinner GCL. This was confirmed in a Spanish study of children with different refraction where the myopic children had significantly thinner GCL thickness than the emmetropic and hyperopic children [17]. In the present study we excluded children with high hyperopia and myopia and hence took away the effect of refraction but still we found a thinner GCL than the large Asian studies.

Previous studies measuring total macular thickness in children has shown a difference according to ethnicity [18]. A more recent study in a large adult Asian cohort showed a significant difference in macular GCL thickness in different ethnic groups where Chinese adults had in average $3.3 \mu \mathrm{m}$ thicker GCL than adults from Indian heritage [19]. It is possible that different ethnicity could be an explanation to the difference in average thickness in the different studies performed with the same type of OCT device. Our narrow inclusion criteria of $+/-3 \mathrm{D}$ may account for this disparity compared to the Asian studies with our participants on average being slightly hyperopic.

In the present study almost, all children were able to perform at least two and often three macula OCTmeasurements and the repeatability between the different measurements were particularly good. Similar results were presented by Muñoz-Gallego et al. however using spectral domain OCT [20]. This indicates that OCT measurements of GCL in the macula is a reliable method and well tolerated in children. The GCL is demonstrating a link between morphology and function when it comes to visual field sensitivity [10]. In children where visual field testing can be challenging a repeated examination over time can be of diagnostic and therapeutical value in patients with optic or central nervous system diseases affecting the visual pathway. This can further make intervention possible before subjective detectable function loss is apparent. Possible diseases suitable to may be optic pathway gliomas as showed by Gu et al. [21] or for screening purposes in neurofibromatosis. Neurologic lesions to the central nervous system affecting the visual pathway can hypothetically be visualized in the retina of children as with adults. In the future modern approaches such as deep learning algorithms can possibly be used to predict loss of central visual field from macular OCT cubes in diseases affecting the visual pathways [22].

\section{Conclusions}

In this study we present normative data of macular GCL in healthy children with normal refraction, spherical equivalent mean:1.13 (sd:0.66) dioptre and normal visual 

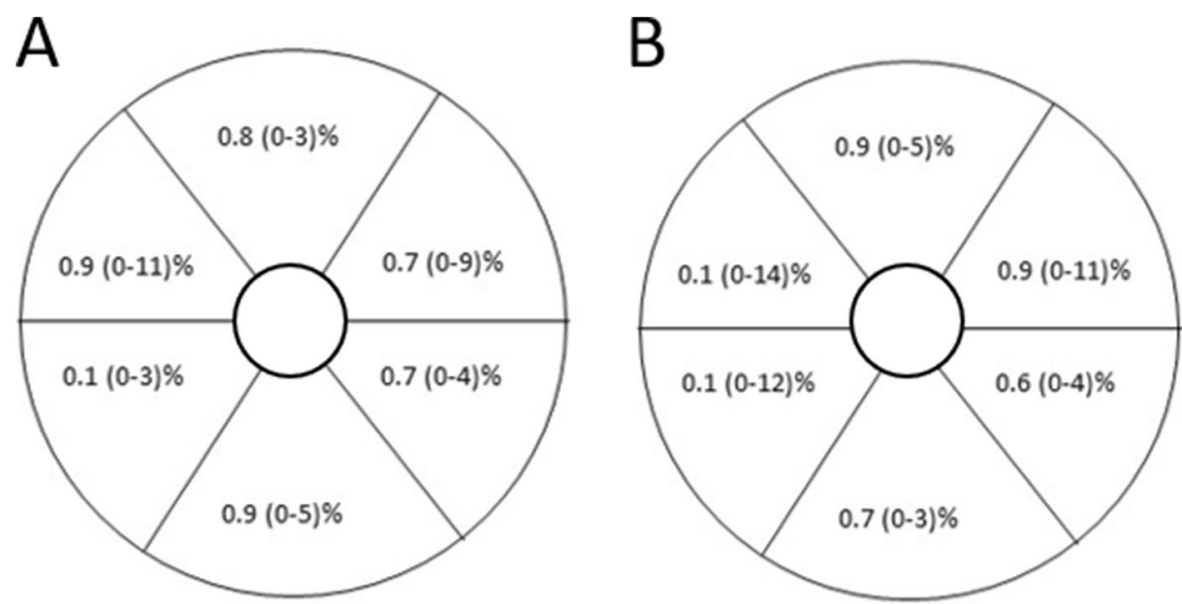

Fig. 3 Median and range coefficient of variation in repeated scans for A. GCIPL (retinal nerve fibre layer/ganglion cell layer boundary to inner plexiform layer/inner nuclear layer boundary) and B. GCC (inner limiting membrane to inner plexiform layer/inner nuclear layer boundary)

acuity Logmar, mean: 0,015 (sd:0,05) using swept source OCT. The OCT measurements of macula GCL showed good $\mathrm{CV}$ and ICC.

The results show reliable measurements which is easy to perform for most children. Further studies will show how we can use the information obtained from macular GCL in diagnosis and follow up of different diseases. Updated normative data for comparison, suited for the intended population of interest, is paramount. We also propose additional fixation targets adapted for children in OCT-devices to increase interest and fixation time during examination.

\section{Abbreviations}

CV: Coefficient of variation; GCL: Ganglion cell layer; GCC: Ganglion cell complex; ICC: Intraclass correlation; ILM: Inner limiting membrane; INL: Inner nuclear layer; IPL: Inner plexiform layer; OCT: Optical coherence tomography; RNFL: Retinal nerve fibre layer; RPE: Retinal pigment epithelium; SE: Spherical equivalent.

\section{Acknowledgements}

Not applicable.

\section{Authors' contributions}

PW, EL and HÅ contributed to the study conception and design. Material preparation, data collection and analysis were performed by PW, EL and HÅ. The first draft of the manuscript was written by PW. All authors read and approved the final manuscript.

\section{Funding}

The study was supported financially by the ARMEC Lindeberg Foundation. The funding body played no role in the design of the study and collection, analysis, and interpretation of data and in writing the manuscript.

\section{Availability of data and materials}

The datasets used and/or analyzed during the current study are available from the corresponding author on reasonable request.

\section{Declarations}

Ethics approval and consent to participate The study was approved by the Regional Ethical Review Committee in Uppsala, Sweden (no. 2018/157). All procedures in the study were in accordance with the ethical standards of the institutional and/or national research committee and the Helsinki declaration and its later amendments. Written informed consent was obtained from all participants in the study. If the participant was younger than 15 years old their caregivers gave written consent and if the participant was older than 15 years they could give their own written consent according to the instruction of the Ethical Committee.

\section{Competing interests}

All authors certify that they have no affiliations with or involvement in any organization or entity with any financial interest or non-financial interest in the subject matter or materials discussed in this manuscript.

\section{Author details}

${ }^{1}$ Department of Ophthalmology, Region Västmanland, Västerås, Sweden. ${ }^{2}$ Department of Surgical Sciences, Uppsala University, Uppsala, Sweden.

${ }^{3}$ Center for Clinical research, Region Västmanland, Västerås, Sweden.

Received: 12 June 2021 Accepted: 19 February 2022

Published online: 08 March 2022

\section{References}

1. Huang D, Swanson EA, Lin CP, Schuman JS, Stinson WG, Chang W, et al. Optical coherence tomography. Science. 1991;254:1178-81. https://doi. org/10.1126/science.1957169.

2. Hee MR, Izatt JA, Swanson EA, Huang D, Schuman JS, Lin CP, et al. Optical coherence tomography of the human retina. Arch Ophthalmol. 1995;113:325-32. https://doi.org/10.1001/archopht.1995.01100030081025.

3. Tan CS, Chan JC, Cheong KX, Ngo WK, Sadda SR. Comparison of retinal thicknesses measured using swept-source and spectral-domain optical coherence tomography devices. Ophthalmic Surg Lasers Imaging Retina. 2015;46:172-9. https://doi.org/10.3928/23258160-20150213-23.

4. Eriksson U, Holmstrom G, Alm A, Larsson E. A population-based study of macular thickness in full-term children assessed with stratus OCT: normative data and repeatability. Acta Ophthalmol. 2009;87:741-5. https://doi. org/10.1111/j.1755-3768.2008.01357.x.

5. Molnar A, Holmstrom G, Larsson E. Macular thickness assessed with spectral domain OCT in a population-based study of children: normative data, repeatability and reproducibility and comparison with time domain OCT. Acta Ophthalmol. 2015;93:470-5. https://doi.org/10. 1111/aos.12695

6. Arnljots U, Nilsson M, Hed Myrberg I, Aden U, Hellgren K. Profile of macular ganglion cell-inner plexiform layer thickness in healthy 6.5 yearold Swedish children. BMC Ophthalmol 20: 329. 2020. https://doi.org/10. 1186/s12886-020-01601-y. 
7. Lee YP, Ju YS, Choi DG. Ganglion cell-inner plexiform layer thickness by swept-source optical coherence tomography in healthy Korean children: normative data and biometric correlations. Sci Rep. 2018;8:10605. https:// doi.org/10.1038/s41598-018-28870-4.

8. Cheng L, Wang M, Deng J, Lv M, Jiang W, Xiong S, et al. Macular ganglion cell-inner Plexiform layer, ganglion cell complex, and outer retinal layer thicknesses in a large cohort of Chinese children. Invest Ophthalmol Vis Sci. 2019;60:4792-802. https://doi.org/10.1167/iovs.18-26300.

9. Bambo MP, Guerri N, Ferrandez B, Cameo B, Fuertes I, Polo V, et al. Evaluation of the macular ganglion cell-inner Plexiform layer and the Circumpapillary retinal nerve Fiber layer in early to severe stages of Glaucoma: correlation with central visual function and visual field indexes. Ophthalmic Res. 2017;57:216-23. https://doi.org/10.1159/000453318.

10. Meier PG, Maeder P, Kardon RH, Borruat FX. Homonymous ganglion cell layer thinning after isolated occipital lesion: macular OCT demonstrates Transsynaptic retrograde retinal degeneration. J Neuroophthalmol. 2015;35:112-6. https://doi.org/10.1097/WNO.00000000000000182.

11. Dinkin M. Trans-synaptic retrograde degeneration in the human visual system: slow, silent, and real. Curr Neurol Neurosci Rep. 2017;17:16. https://doi.org/10.1007/s11910-017-0725-2.

12. Jindahra P, Petrie A, Plant GT. Retrograde trans-synaptic retinal ganglion cell loss identified by optical coherence tomography. Brain. 2009;132:628-34. https://doi.org/10.1093/brain/awp001.

13. Ahn HC, Son HW, Kim JS, Lee JH. Quantitative analysis of retinal nerve fiber layer thickness of normal children and adolescents. Korean J Ophthalmol. 2005;19:195-200. https://doi.org/10.3341/kjo.2005.19.3.195.

14. Larsson E, Molnar A, Holmstrom G. Repeatability, reproducibility and interocular difference in the assessments of optic nerve OCT in childrena Swedish population-based study. BMC Ophthalmol. 2018;18:270. https://doi.org/10.1186/s12886-018-0940-x.

15. Hedin A, Olsson K. Letter legibility and the construction of a new visual acuity chart. Ophthalmologica. 1984;189:147-56. https://doi.org/10.1159/ 000309402.

16. Totan $Y$, Guragac FB, Guler E. Evaluation of the retinal ganglion cell layer thickness in healthy Turkish children. J Glaucoma. 2015;24:e103-8. https://doi.org/10.1097/JGG.0000000000000168.

17. Del-Prado-Sanchez C, Seijas-Leal O, Gili-Manzanaro P, Ferreiro-Lopez J, Yanguela-Rodilla J, Arias-Puente A. Choroidal, macular and ganglion cell layer thickness assessment in Caucasian children measured with spectral domain optical coherence tomography. Eur J Ophthalmol. 2020;1120672120965486. https://doi.org/10.1177/1120672120965486.

18. Tariq YM, Li H, Burlutsky G, Mitchell P. Ethnic differences in macular thickness. Clin Exp Ophthalmol. 2011;39:893-8. https://doi.org/10.1111/j.14429071.2011.02593.x.

19. Tham YC, Chee ML, Dai W, Lim ZW, Majithia S, Siantar R, et al. Profiles of ganglion cell-inner Plexiform layer thickness in a multi-ethnic Asian population: the Singapore epidemiology of eye diseases study. Ophthalmology. 2020;127:1064-76. https://doi.org/10.1016/j.ophtha.2020.01.055.

20. Munoz-Gallego A, De la Cruz J, Rodriguez-Salgado M, Torres-Pena JL, Sambricio J, Ortueta-Olartecoechea A, et al. Interobserver reproducibility and interocular symmetry of the macular ganglion cell complex: assessment in healthy children using optical coherence tomography. BMC Ophthalmol. 2020;20:197. https://doi.org/10.1186/s12886-020-01379-z.

21. Gu S, Glaug N, Cnaan A, Packer RJ, Avery RA. Ganglion cell layer-inner plexiform layer thickness and vision loss in young children with optic pathway gliomas. Invest Ophthalmol Vis Sci. 2014;55:1402-8. https://doi. org/10.1167/iovs.13-13119.

22. Mohammadzadeh V, Fatehi N, Yarmohammadi A, Lee JW, Sharifipour F, Daneshvar R, et al. Macular imaging with optical coherence tomography in glaucoma. Surv Ophthalmol. 2020;65:597-638. https://doi.org/10. 1016/j.survophthal.2020.03.002.

\section{Publisher's Note}

Springer Nature remains neutral with regard to jurisdictional claims in published maps and institutional affiliations.
Ready to submit your research? Choose BMC and benefit from:

- fast, convenient online submission

- thorough peer review by experienced researchers in your field

- rapid publication on acceptance

- support for research data, including large and complex data types

- gold Open Access which fosters wider collaboration and increased citations

- maximum visibility for your research: over $100 \mathrm{M}$ website views per year

At BMC, research is always in progress.

Learn more biomedcentral.com/submissions 